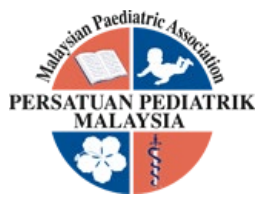

\title{
A VIRTUAL PET SERIOUS GAME IN MOTIVATING CHILDREN WITH CANCER IN TREATMENT AND SELF-CARE: A CONCEPTUAL DESIGN
}

\author{
Carmen Chai Wang Er ${ }^{1}$, Lau Bee Theng ${ }^{1}$, Abdullah Al Mahmud ${ }^{2}$, Mark Tee Kit Tsun'
}

\begin{abstract}
Childhood cancer is the number one cause of death by illness in children. However, despite being such a deadly disease, survival from childhood cancer is high with cancer treatment. Unfortunately, undergoing cancer treatment can result in many treatments related side-effects. Daily self-care such as maintaining a balanced diet, drinking enough fluids, practicing proper hygiene and getting enough rest, can be effective in lowering the severity of these symptoms. It is found that existing interventions for cancer patients do not target treatment adherence in children. Therefore, the aim of the research is to design an intervention which is able to motivate children to adhere to treatment and encourage daily self-care. To enhance the design of such an intervention, the article explores the potential of virtual pet games as a health intervention, and the use of the Protection Motivation Theory and Social Learning Theory's observational learning in increasing the intervention's effectiveness. Finally, the design considerations, game objectives and overall conceptual architecture of the proposed intervention are discussed. A conceptual comparison is also made between the proposed game and existing serious games for cancer patients. Future work is required to develop this design into a working prototype, and to evaluate its effectiveness on improving treatment adherence and promoting daily self-care with childhood cancer patients.
\end{abstract}

Keywords: Childhood cancer, observational learning, protection motivation theory, serious games, virtual pet.

\section{Introduction}

Childhood cancer is a deadly illness. However, young cancer patients have a high chance of survival with cancer treatment. Unfortunately, cancer treatment often results in many treatment side-effects such as pain, fatigue, sleep-related problems, and nausea, which can cause these young patients to not adhere to their treatment. To reduce the severity of these side effects, it is important for cancer patients to practice proper daily self-care. Serious games are games with additional objectives besides entertaining the player [1]. Existing serious games for cancer patients that have been reviewed for their objectives, have shown that there is a lack of intervention for motivating treatment adherence in children, and for encouraging daily self-care. A patient and his or her family are considered to
Received: 07 September 2020; Accepted revised manuscript: 11 November 2020

Published online: 08 December 2020

adhere to treatment when they follow treatment instructions from the health care professional, such as taking medication on time and going for therapy sessions [2]. Therefore, this study aimed to design an intervention for motivating children with cancer to adhere to cancer treatment and promote daily self-care.

\footnotetext{
${ }^{1}$ Faculty of Engineering, Computing and Science, Swinburne University of Technology Sarawak Campus, Jalan Simpang Tiga, 93350 Kuching, Sarawak, Malaysia ${ }^{2}$ Faculty of Health, Arts \& Design, Swinburne University of Technology, Melbourne, Victoria, Australia

Corresponding author: Carmen Chai Wang Er, Faculty of Engineering, Computing and Science, Swinburne University of Technology Sarawak Campus, Jalan Simpang Tiga, 93350 Kuching, Sarawak, Malaysia. Tel: +6082260686

Email: cchai@swinburne.edu.my
} 


\section{Background}

Childhood cancer has a survival rate of $80 \%$ in high-income countries, however it is still the most prevalent cause of death in children via illness [3]. For many young patients, being diagnosed with cancer and needing to go through the long treatment process is a challenging and difficult experience [4]. In addition, cancer treatments such as radiotherapy and chemotherapy can cause many treatment side-effects [5-7]. These factors can result in treatment non-adherence and even treatment abandonment by childhood cancer patients and or their families [2]. However, in order to have higher chances of survival, it is of great importance that cancer patients comply with their treatment.

\section{Managing Side-Effects through Daily Self-Care}

Daily self-care plays a major role in making the cancer treatment process more bearable for childhood cancer patients. Patients will be more likely to adhere to treatment if the treatmentrelated side effects can be managed. This section discusses the various ways healthy habits can help with the management of various treatmentrelated side effects.

First, maintaining a balanced diet. One common treatment side effect is malnutrition, which is exacerbated by other treatment side effects such as dry mouth, nausea, vomiting, constipation, and taste changes [8]. Malnutrition, or the lack of proper nutrition can lead to poor survival rates $[9,10]$. In some cases, malnutrition has also resulted in treatment abandonment [11]. In order to go through the cancer treatment process eventfree, childhood cancer patients must maintain a balanced and healthy diet to get proper nutrition.

Second, drinking enough fluids each day. Dehydration can result from not getting enough water. Mild dehydration causes constipation, dizziness, nausea, fatigue and dry mouth, all of which can worsen common cancer and treatment symptoms such as vomiting, fever, and diarrhoea [12]. With proper fluid management, one will be able to keep well-hydrated, maintain a normal volume of blood in the body, as well as good electrolyte balance [13].

Next, maintaining of good hygiene. Practising good bodily hygiene can help prevent infections and getting illnesses in cancer patients due to their weaker immune systems. It has been recommended that cancer patients bathe at least once a day and wash body parts that are prone to sweatiness such as the armpits, the groin, and the feet [14]. On the other hand, practising good oral hygiene can help reduce many symptoms of the common treatment side effect, mucositis. The minimal oral hygiene of brushing one's teeth twice a day with fluoride toothpaste using a soft toothbrush is recommended to lessen mucositis related symptoms such as ulcers, cracked lips, dry mouth, and peeling of the palate, oral mucosa and gums [7].

Another important daily self-care act is to be well rested. Sleep is known to help with the maintaining of health-related quality of life in childhood cancer patients. It has been found that getting proper rest can improve the abilities of young cancer patients to cope with having the illness, as well as the stress, depression, and anxiety that may come with it [15].

In addition to the above discussed daily self-care actions, childhood cancer patients are also encouraged to share their thoughts, worries, and experiences to their family and friends. It has been shown that adolescents who were able to creatively express their needs were able to cope more positively with having cancer [16]. Sharing one's experiences with a difficult experience is shown to calm feelings of uncertainty, worry, and anxiety, and also empowers young patients in fighting the illness [17].

Finally, as going through cancer treatment is a distressing experience, childhood cancer patients are encouraged to take part in physical activities and also play. Having regular playtimes can help give these young patients an outlet for their distress [18]. Even the act of playing video games that does not involve physical activities was also found to be of therapeutic value to children with chronic illness [19].

\section{Serious Games}

As video games are shown to benefit children with chronic illness, such as cancer, the serious game is perceived as a potential intervention method. Serious games are games that have been built with additional objectives on top of entertaining the players. These additional objectives include 
gaining knowledge, improving lifestyle behaviour, skills and abilities, and raising awareness on difficult topics $[1,20,21]$.

Serious games have also been used as health games for patients. The five main objectives of these serious games are health monitoring, rehabilitation to restore health and life skills, treatment or therapy to manage or improve the condition of the illness, education on the illness to improve coping, and detection of irregular symptoms [1].

A review on serious games for young chronic illness patients revealed that playing these games could improve patients' knowledge on the disease and also self-management [22]. Additionally, frequent gaming among adolescents and young adults with long-term illnesses have shown that these players were able to benefit from their hobby as it improves their ability to face the daily challenges of having a disease such as cancer [23].

\section{Serious games for cancer patients}

Serious games have been developed and used as interventions for cancer patients. This section lists various serious games and their objectives.

Ben's Game [24] is a shooter game for children with cancer where players can go inside their body to fight bosses based on common cancer symptoms. This computer game has the objective of educating players about common cancer symptoms as well as empowering the player to fight against cancer. Children who have played the game have reported that the game has taught them about common cancer symptoms, and those who have cancer have also noted that the game has given them more confidence to fight cancer [25].

Cytarius is a strategy game for adolescents with cancer where players can save multiple planets by deploying fighters based on cancer treatments to fight off the invasion of cancer cells. The computer game's objective is to convey information on cancer and cancer treatment to young patients so that they can better understand and participate in discussions involving their health with their parents and medical staff. The game has been well received among young cancer patients as they enjoyed the game and story. It also helped the players to better understand cancer treatment [26].

Empower Stars! is an exergame for children with cancer which is playable on a tablet device. An exergame is by definition, a game which involves physical activity to play [28]. Like every exergame, this game has the objective to promote physical activities among young cancer patients as it incorporates 20 minutes of physical activity into its 30 minute long game play. Through exercising and solving puzzles, players will be able to save a barren planet from the cercer crabs, which are the embodiment of cancer cells that serve as enemies to the player in this game. Additionally, the game aims to educate players about cancer treatments. Prototype testing of this game showed that children enjoyed playing the game, including the exercise it provided [27].

iManageCancer platform contains two serious games for cancer patients. The first game is to help adult cancer patients and is a town management mobile game. In this game the player takes the role of the mayor of a town and uses its resources to solve the various problems of the townspeople. The game's objective is to encourage good health habits and teach the players to make better lifestyle choices regarding their health. The second game is for children with cancer is a space shooter game. In this game, the players can shoot down cancer cells. This lets players virtually fight cancer which helps with the game objective of empowering patients during the cancer treatment experience. There is currently no report of the result of playing the two serious games from the iManageCancer platform [29].

ILOVEBREAST, is a life management mobile game for metastatic breast cancer patients who plan to use cytotoxic chemotherapy. In this game, players can take care of their avatars who are also diagnosed with breast cancer through the daily self-care such as exercising, eating healthily, and taking chemotherapy medications on time. The game's objective is to improve drug adherence and decrease the side-effects of going through chemotherapy via good health habits. Intervention results showed that the players of the game displayed better drug adherence, decreased side effects from treatment, and improved knowledge on cancer and cancer treatment compared to those that studied a conventional breast cancer and treatment education booklet [30]. 
Re-mission [31] is a shooter computer game for adolescents and young adults with cancer who are taking oral chemotherapy. It features a nanobot shooting down cancer cells and managing symptoms inside virtual patients' bodies. The game aims to increase treatment adherence for chemotherapy medication intake, promote management of common symptoms, increase cancer-related knowledge of players, and improve self-efficacy of players to take care of themselves during cancer $[32,33]$. Results of the intervention showed that compared to other cancer patients, players of the game displayed better treatment adherence, greater knowledge on cancer treatments and side-effect management, and more confidence to take care of themselves during cancer [31].

As seen above, serious games for cancer patients have the potential to help the players in various ways. As important as adhering to cancer treatment is for the survival of childhood cancer, many serious game interventions do not have treatment adherence as their game objective. The two interventions on this list that aimed to boost treatment adherence in terms of taking medication are ILOVEBREAST and Re-mission. Both games have inspired the development of the conceptual design discussed in this paper as they have the same objectives. However, both games were designed for older age groups such as adolescents and adults rather than children, who are the main target audience of the conceptual game designed. Both games also targeted drug adherence specifically and did not cover other common cancer treatments such as radiotherapy and surgery.

Additionally, with daily self-care being effective for managing treatment side effects, game genres that demonstrate daily self-care such as life management games and virtual pet games should be considered. As a study has found that children enjoy animal game characters in games [34], the virtual pet game genre is explored.

\section{Virtual pet serious games for health}

A virtual pet is an electronic toy, robot, or game that emulates a real pet that humans can interact with [35]. Virtual pets have been used as health interventions for children to promote health management and good health habits.
The first example is Wizdy Pets, a virtual pet game that has been developed to teach children about asthma. The game features a dragon with asthma who needs to keep its asthma in check otherwise it wouldn't be able to breathe fire. The game educates about the proper way to use an inhaler, identifying asthma triggers, and identifying the warning signs of an impending attack. As the players take care of and learn about the dragon's needs, they will become more aware of their own needs as well, especially towards asthma management [36].

The second example consists of two virtual pet games that have been used to encourage healthy habits to prevent obesity in children $[37,38]$. These interventions utilized the human-animal bond that children have with animals, even virtual ones, to boost their motivation to adhere to healthy habits. The healthy habits targeted by the two virtual pet game interventions are eating more fruits and vegetables, and carrying out more physical activities.

\section{Increasing player engagement}

To encourage players to keep playing the serious game intervention during the cancer treatment period, ways to increase player engagement must be implemented. Before the players are able to become more invested in a game, they must first experience the basic involvement of being engaged [39]. Once engagement happens, players will have the desire to continue playing the game.

A popular method of engagement is to include a reward and incentive system within the game $[40,41]$. Examples of rewards commonly found in games are virtual items, achievements, quests, and avatars. Avatars are often used as a strong incentive for players due to the ability to customize the appearance of the playable character. The more similarities the players have with their avatars, the more they would identify with it, which in turn improves the game engagement with the players [42].

Another method of engaging players is through appointment mechanics, which are used to motivate players to revisit the game to keep playing. Examples of appointment mechanics used in casual games are daily quests and consecutive login calendar rewards [43]. 


\section{Research Theory for Intervention Design}

There is a need for suitable research theories to base the intervention design on. In this section, the Protection Motivation Theory and the Social Learning Theory are reviewed as potential guides in increasing the effectiveness of such an intervention.

\section{Protection motivation theory}

The Protection Motivation Theory (PMT) [44] is a health belief model that is used as a way to determine a person's intention to take up a protective action or behaviour against a health threat. The person's intention consists of seven factors that are divided into two different categories: the threat appraisal, and the coping appraisal.

The threat appraisal includes the factors of perceived severity of the threat, perceived vulnerability towards the threat, intrinsic/extrinsic rewards of engaging in the behaviour that encourages the threat, for example: the feelings of addiction (intrinsic reward) and also acceptance by peers (extrinsic reward) for engaging in the activity of smoking which can result in the threat of lung cancer, and fear arousal from the threat.

On the other hand, the coping appraisal consists of the perceived response efficacy, or how effective the response is, perceived self-efficacy, or how confident the person is about carrying out the response, and the response cost, or how much it would cost the person to take up the response against the threat. The response cost can consist of more than monetary cost, where even feelings of embarrassment and discomfort from taking up the response are considered as valid response costs.

The Protection Motivation Theory has been incorporated into the design of serious games e.g. A serious game to boost the emergency preparedness of during a terror attack [45]. Thus, the researchers see the novelty of incorporating PMT into the design of health-based serious games. Therefore, health education interventions based on the PMT have been reviewed to demonstrate the applicability and adaptability of PMT-based interventions in motivating good behaviours in health.

The Protection Motivation Theory has been used as a base for interventions to boost health behaviour in participants in protecting themselves from a health threat. Examples are interventions to promote physical activities [46], reduce skin cancer risk in high school students [47], to promote knowledge of melanoma risk and prevention among children with familial risk for melanoma [48]. All these interventions have successfully improved knowledge of participants to their health risks and to the protective measures they can take, and also encouraged health behaviours.

In the case of the intervention of this study, the Protection Motivation Theory can be used as a guide to boost the belief of young cancer patients going through cancer treatments, which will ultimately help them to effectively deal with the cancer threat.

Focusing on the threat appraisal may result in further distress in young cancer patients who have the deadly illness. Therefore, the intervention will focus on the coping appraisal aspect of the Protection Motivation Theory.

For the intention of young cancer patients to use cancer treatment as a protective action against the cancer threat, the intervention should improve response-efficacy, which is how effective the patients' perceived cancer treatment is in fighting cancer. The intervention should also improve selfefficacy, which is the belief of the patients in themselves to keep up with the cancer treatment. Lastly, the intervention should lower the response cost of taking up cancer treatment as a response, which are the treatment side effects. This response cost can be lowered with the practice of good daily self-care.

This leads to the intention of young cancer patients to use daily self-care as a protective action against the treatment side effects threat. The intervention should improve the response efficacy of young patients so that they will become aware that daily self-care is important in reducing the severity of treatment related side effects. The intervention should also improve the self-efficacy or confidence of young patients to perform their daily self-care needs. The foreseeable response cost of using daily self-care is the time and effort taken to perform these actions. However, as the intervention will not be able to improve this, the response cost factor for using daily self-care will not be included in the intervention's design.

With these factors taken into consideration in the design, the Protection Motivation Theory-based 
intervention may help in achieving the study's objective of improving motivation of childhood cancer patients in adhering to their treatment and promoting daily self-care.

\section{Social learning theory}

There is a need to convey the practice of good health habits during cancer treatment. The Social Learning Theory [49] hypothesizes that people are able to pick up new information, actions and behaviours from one another through imitation, observation, and modelling.

One aspect of the Social Learning Theory is observational learning, also known as vicarious learning [50]. Observational learning can be learnt through three basic models, a live model, a verbal instructional model, and a symbolic model involving real or fictional characters demonstrating behaviours through media such as videos, books, and games. Learning from the symbolic model means that even without needing to experience the feedback directly, people are able to learn actions and behaviours just from watching the actions of these characters [51].

Through observational learning, it is possible to encourage healthy habits such as daily self-care through a symbolic model: the game character or avatar. An example of a serious game developed for young children that uses observational learning is "Veggie Maths Masters" [52]. The game has successfully encouraged liking and eating vegetables in young children who have played the game by showing them pictures of vegetables and featuring characters that enjoy eating vegetables. These vegetable-loving characters serve as symbolic models in observational learning as they demonstrated a behaviour that the game wishes the children to learn, which is to eat vegetables. This shows that Social Learning Theory's observational learning is suitable for even young children to pick up health behaviours from playing a game.

Therefore, observational learning may be used in the intervention for childhood cancer patients to convey the positive effects of practicing daily selfcare. This will help promote daily self-care among the players to reduce treatment related side effects.

\section{Design of Virtual Pet Serious Game Prototype}

It has been established that playing video games is beneficial to patients with chronic illness. However, as shown in the review of serious games for cancer patients, it is apparent that many such interventions do not focus on promoting treatment adherence and daily self-care among childhood cancer patients.

One game genre that includes the aspect of daily self-care is the virtual pet game where the player will have to take care of the virtual pet's daily needs. Virtual pet games have the potential of being good health interventions for children, as it has been used to educate about asthma management, and to encourage healthy habits.

Therefore, we postulate that the game prototype proposed as the intervention for children with cancer should be a virtual pet serious game. The game should be designed to improve the motivation of childhood cancer patients to adhere to treatment and promote the practice of daily self-care. The design considerations are as follow.

The game should be based on the Protection Motivation Theory to improve the coping appraisal of young cancer patients to use cancer treatment as a response against the cancer threat. The game should increase the response efficacy by bridging the medical knowledge gap of children regarding cancer and cancer treatment. This will help them become aware that adhering to their cancer treatment is important for fighting cancer. The game should also increase the self-efficacy of childhood cancer patients by allowing them to fight cancer through mini-games based on real cancer treatments. This will boost their confidence in going through these treatments in real life. Finally, the game would also reduce the response cost of taking up cancer treatment by encouraging daily self-care in order to lower the severity and occurrence of treatment related side effects.

The game intervention should also be based on observational learning by providing the virtual pet as a symbolic model of someone engaging in good daily self-care while going through cancer treatment. As the children take care of the needs of their pet, they will learn that daily self-care is an important part of maintaining good health while undergoing cancer treatment.

Additionally, as the game intervention is expected to be played over a long period of time during 
cancer treatment, it should include reward systems as well as appointment mechanics to engage and increase the continuation desire of players.

Another design consideration is for the game intervention to be a mobile game. Serious games are recommended to be in the form of a mobile game due to the high acceptance rates of smartphone games [53]. Young children are also found to be adept at the use of interactive technology and were able to handle mobile devices such as phones and tablets on their own at a very young age $[54,55]$. Mobile games also have the advantage of being easily accessible at any time and place.

The last design consideration of the proposed solution is for the game to be of casual nature. It has been recommended that serious game interventions for young patients with heavy treatment plans be easy to pick up and put down [26]. This will encourage the patient to play the game even on busy or low energy days. Additionally, casual games do not require long time commitments to make progress and are often easy to learn and play, which is important as this intervention targets children and adolescents who are undergoing cancer treatment.

\section{Game Objectives, Game Modules and PMT Factors}

In order to achieve the primary intervention, aim of improving motivation of children to adhere to treatment, the serious game should include the following game objectives. In this research, we explore the possible game objectives, related game modules and related Protection Motivation Theory coping appraisal factors of the virtual pet game.

The first game objective is to increase knowledge on cancer, cancer treatment, and daily self-care. This can be achieved through educational modules such as a library module where players can read up on these topics, and a quiz mini game to test the knowledge of players regarding these topics. By improving the players' knowledge on cancer treatment, it will improve the response efficacy for using cancer treatment. Additionally, as players about their health and emotional situation, allowing them to reflect on their situation. With the pet serving as a companion of going through learn more about how daily self-care is able to help in reducing treatment side effects and making them healthier, it will improve the response efficacy for daily self-care.

Next, the game should improve treatment adherence. This can be achieved through the game module of mini games that have been modelled after real cancer treatments. As players play these mini games, their attitude towards the cancer treatments will become more positive. This will improve the players' response efficacy for using cancer treatment.

Additionally, the game should also empower players to fight cancer. Thus, this can be achieved through the mini games that have been modelled after real cancer treatments. As players are able to virtually fight cancer when playing these mini games, it will empower them in their fight against cancer and improve their self-efficacy for going through cancer treatment. Other game modules that can provide empowerment are the pet module, and the care actions module. On top of using cancer treatment to fight cancer, taking care of themselves during the cancer treatment process is also one way the player can fight against the illness. In the game, the pet can serve as a symbolic model of fighting cancer by taking care of one's health during the treatment process. As the players take care of the pet, they will gain the confidence to take care of themselves during their own cancer treatment. This will improve the players' self-efficacy for both cancer treatment and daily self-care.

Besides that, the game should also help the players through providing reminders for daily selfcare and cancer treatment. This can be achieved through an alarm module which will allow players to set reminders for things such as meal times, bed times, medication times, and even doctor's appointment times. With the reminders, the players shall gain confidence in themselves and improve the self-efficacy for cancer treatment and daily self-care.

Another game objective is to encourage the sharing of thoughts during the cancer treatment experience. The game can contain a diary module for this where the players can write to their pets

the hardship of cancer treatment together, being able to share their feelings to the pet shall help the players gather strength to keep up with their 
cancer treatment and daily self-care. This improves the self-efficacy of the player for cancer treatment and daily self-care.

Finally, the game should encourage healthy habits. This is achieved through the pet module, care actions module, and pet status module. Within virtual pet games, the pet's care status is often displayed for the player to see. As time passes in the day, the value of these statuses will drop and can be recovered when the players take care of the pet's needs. Through observational learning, the players can see that if they take good care of the pet, the pet's status will be healthy. This may encourage players to take care of their own daily self-care needs which can help in the management of treatment side effects. In addition, this may improve the response efficacy and self-efficacy for daily self-care of the players, as well as reducing the response cost of treatment related side effects from using cancer treatment to fight cancer.

\section{Conceptual Architecture}

The game design requirements, objectives and modules have been incorporated into the conceptual design of the virtual pet game intervention model in Figure 1.

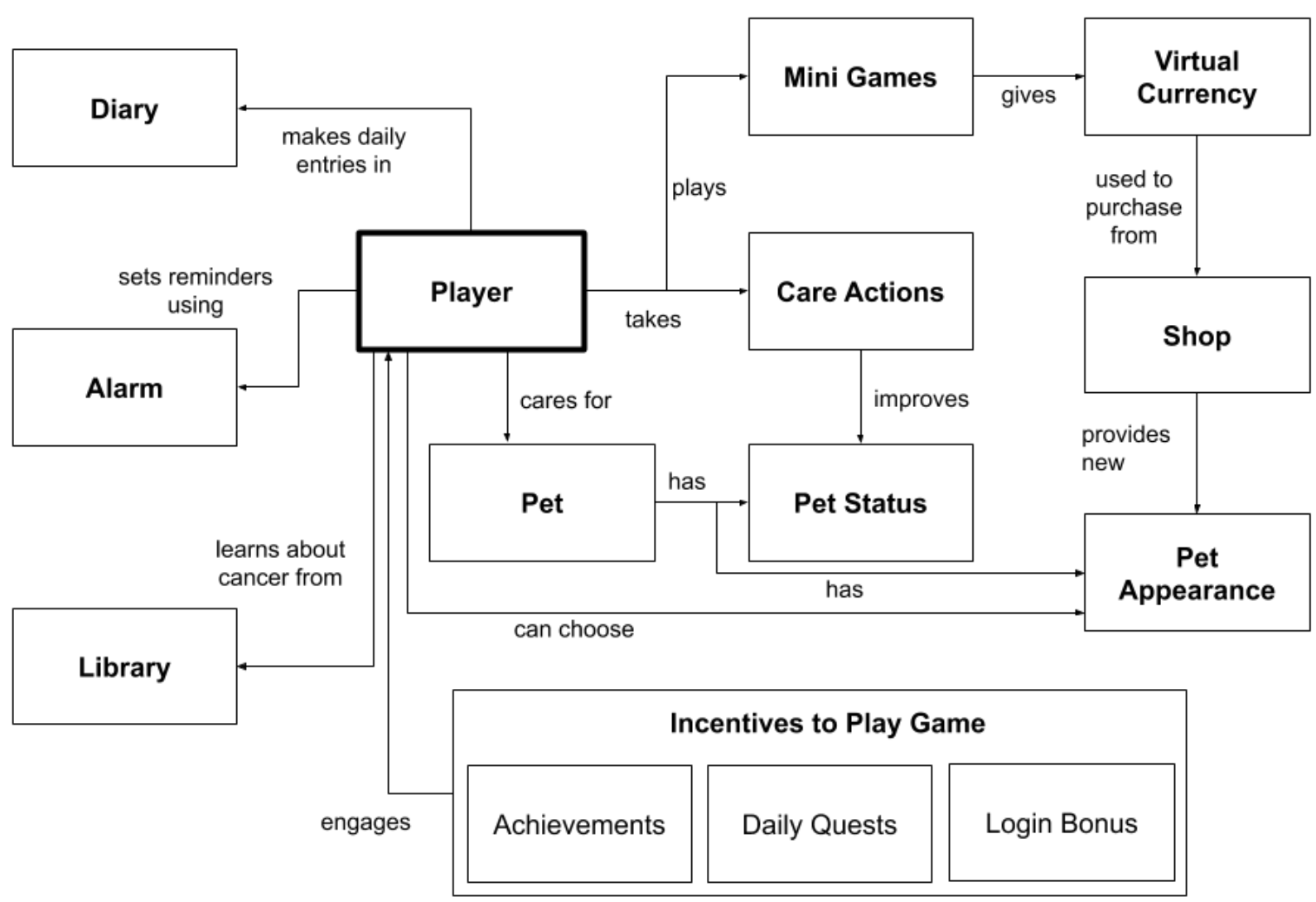

Figure 1. Conceptual model of the virtual pet game intervention. 
In the virtual pet game, the player needs to care for the pet which has pet status such as hunger, thirst, cleanliness, and rest. The player can take care actions to care for the pet's daily needs and improve the pet's status values. The player can also customize the pet's appearance, which is one way of improving engagement of players with a game. The player can play mini games which consist of mini games based on cancer treatment that allow the player to virtually fight cancer, and a quiz based mini game on cancer and related facts. Playing mini games provides the player with virtual currency that can be used to purchase even more pet appearance options from the shop for the pet, serving as further incentive to play.

Besides the core modules involving the pet, additional modules in the game designed include the diary module where the player can make daily entries in, the alarm module where the player can set reminders for daily self-care needs and cancer treatment related needs, and the library module where the player can learn more about cancer, cancer treatment and daily self-care.

Finally, there are modules added to the game to further engage the player through game rewards and appointment mechanics such as the achievements module, the daily quests module, and the consecutive login bonus module.

\section{A Comparison of the Proposed Game Model with Existing Serious Games for Cancer Patients}

Table 1 below compares the proposed virtual pet serious game for children with cancer with existing serious games for cancer patients in terms of the game objectives of the proposed game. A comparison is made as well on whether the games target children, whether the game is available on mobile, whether the game has a virtual rewards system, and whether the game provides a symbolic model of someone going through cancer.

It is significant that many of the existing cancer related serious games do not accommodate majority of the objectives and game requirements in our proposed game model. Only two serious games, ILOVEBREAST and Re-mission, have the same main objectives as the proposed game, which are to promote treatment adherence, and to encourage healthy habits.
Even though both ILOVEBREAST and Re-mission do target treatment adherence, only drug/medication adherence is focused on, while the proposed game aims to improve treatment adherence for the three common treatment methods which are chemotherapy, radiotherapy and surgery. In addition, ILOVEBREAST's target players are adults with breast cancer and is therefore not suitable to address childhood cancer. Re-mission also targets older players which are adolescents and young adults with cancer. Additionally, Re-mission is only available for computers, making it more difficult to access compared to the mobile platform. Re-mission also does not have a virtual reward system to increase player engagement and does not provide a symbolic model of someone going through cancer which can aid in the conveying of healthy habits. 
Table 2. Proposed Game vs Existing Serious Games for Cancer Patients

\begin{tabular}{|c|c|c|c|c|c|c|c|c|}
\hline & $\begin{array}{c}\text { Proposed } \\
\text { Game }\end{array}$ & $\begin{array}{l}\text { Ben's } \\
\text { Game }\end{array}$ & Cytarius & $\begin{array}{l}\text { Empow } \\
\text { er Stars! }\end{array}$ & $\begin{array}{c}\text { iManage } \\
\text { Cancer } \\
\text { (adult) }\end{array}$ & $\begin{array}{l}\text { iManage } \\
\text { Cancer } \\
\text { (children) }\end{array}$ & $\begin{array}{l}\text { ILOVE } \\
\text { BREAST }\end{array}$ & $\begin{array}{c}\text { Re- } \\
\text { mission }\end{array}$ \\
\hline $\begin{array}{l}\text { Promote } \\
\text { treatment } \\
\text { adherence }\end{array}$ & $\begin{array}{c}\text { General } \\
\text { cancer } \\
\text { treatment } \\
\text { adherence }\end{array}$ & $x$ & $x$ & $x$ & $x$ & $x$ & $\begin{array}{c}\text { Drug } \\
\text { adherence }\end{array}$ & $\begin{array}{c}\text { Drug } \\
\text { adherence }\end{array}$ \\
\hline $\begin{array}{l}\text { Encourage } \\
\text { healthy habits }\end{array}$ & Self-care & $x$ & $x$ & $\begin{array}{l}\text { Physical } \\
\text { activity }\end{array}$ & $\begin{array}{l}\text { General } \\
\text { lifestyle } \\
\text { health } \\
\text { choices }\end{array}$ & $x$ & Self-care & Self-care \\
\hline $\begin{array}{l}\text { Increase } \\
\text { knowledge on } \\
\text { cancer and } \\
\text { related topics }\end{array}$ & $\checkmark$ & $\checkmark$ & $\checkmark$ & $\checkmark$ & $\checkmark$ & $x$ & $\checkmark$ & $\checkmark$ \\
\hline $\begin{array}{l}\text { Empower } \\
\text { players to fight } \\
\text { cancer }\end{array}$ & $\checkmark$ & $\checkmark$ & $\checkmark$ & $\checkmark$ & $\checkmark$ & $\checkmark$ & $\checkmark$ & $\checkmark$ \\
\hline $\begin{array}{l}\text { Provide } \\
\text { reminders for } \\
\text { healthy habits }\end{array}$ & $\begin{array}{c}\text { Daily self- } \\
\text { care, } \\
\text { medication } \\
\text { and doctor's } \\
\text { appointments }\end{array}$ & $x$ & $x$ & $x$ & $x$ & $x$ & Medication & $x$ \\
\hline $\begin{array}{l}\text { Encourage } \\
\text { sharing of } \\
\text { thoughts } \\
\text { during cancer } \\
\text { treatment }\end{array}$ & $\begin{array}{c}\text { Provides a } \\
\text { diary module }\end{array}$ & $x$ & $x$ & $x$ & $x$ & $x$ & $x$ & $x$ \\
\hline $\begin{array}{l}\text { Targets } \\
\text { children }\end{array}$ & $\checkmark$ & $\checkmark$ & $\checkmark$ & $\checkmark$ & $\mathrm{x}$ & $\checkmark$ & $x$ & $x$ \\
\hline $\begin{array}{l}\text { Available on } \\
\text { mobile } \\
\text { platform }\end{array}$ & $\checkmark$ & $x$ & $\checkmark$ & $\checkmark$ & $\checkmark$ & $\checkmark$ & $\checkmark$ & $x$ \\
\hline $\begin{array}{l}\text { Virtual reward } \\
\text { system }\end{array}$ & $\checkmark$ & $\checkmark$ & $x$ & $\checkmark$ & $\checkmark$ & $\checkmark$ & $\checkmark$ & $x$ \\
\hline $\begin{array}{l}\text { Provide a } \\
\text { symbolic } \\
\text { model of } \\
\text { someone } \\
\text { going through } \\
\text { cancer }\end{array}$ & $\checkmark$ & $x$ & $x$ & $x$ & $x$ & $x$ & $\checkmark$ & $x$ \\
\hline
\end{tabular}




\section{Conclusion and Future Work}

Treatment adherence towards childhood cancer treatment is essential to survival. However, treatment non-adherence may occur due to high treatment side effect burdens. These side effects can be managed with proper daily self-care. Yet, there is a lack of intervention for cancer patients that target treatment adherence in children.

Therefore, it is proposed that an intervention for motivating childhood cancer patients to adhere to treatment should be designed and developed. This article introduces the concept of a Protection Motivation Theory-based virtual pet serious game for the improvement of childhood cancer patients' motivation to adhere to their treatment and perform daily self-care. The proposed game utilizes observational learning by having the pet as a symbolic model to the player to show the importance of taking care of one's daily self-care needs during cancer treatment. The proposed game's objectives include (1) increasing knowledge on cancer, cancer treatment, and daily self-care, (2) to improve treatment adherence, (3) empowering players to fight cancer, (4) to provide reminders for daily self-care and cancer treatment, (5) encouraging sharing of players' thoughts during the cancer treatment experience, and (6) encouraging healthy habits. The game is also proposed to be a mobile game of casual nature, containing virtual rewards to engage the players.

Future work of this study includes the development of the virtual pet serious game prototype based on the design discussed in this article. Additionally, the game intervention could be evaluated and assessed using pre- and postintervention surveys developed based on the Protection Motivation Theory with childhood cancer patients to determine effectiveness in improving motivation to adhere to treatment. A longitudinal study should be done to establish the causal-effect relationship of the intervention and treatment adherence and self-care routine.

\section{References}

[1] Wattanasoontorn V, Boada I, García R, Sbert M. Serious games for health. Entertain. Comput. 2013; 4(4), 231-47. doi:10.1016/j.entcom.2013.09.002
[2] SIOP Working Committee on Psychosocial Issues in Pediatric Oncology. Guidelines for refusal, non-compliance and abandonment of treatment in children and adolescents 2002; https://www.childhoodcancerinternational.or g/guidelines-for-refusal-non-complianceand-abandonment-of-treatment-in-childrenand-adolescents/.

[3] Pritchard-Jones K, Pieters R, Reaman GH, Hjorth L, Downie P, Calaminus $G$, et al. Sustaining innovation and improvement in the treatment of childhood cancer: Lessons from high-income countries. Lancet Oncol. 2013; 14(3), e95-103. doi:10.1016/S14702045(13)70010-X

[4] Friedrich P, Lam CG, Kaur G, Itriago E, Ribeiro RC, Arora RS. Determinants of treatment abandonment in childhood cancer: Results from a global survey. PLoS One 2016; 11(10), e0163090. doi:10.1371/journal.pone.0163090

[5] McCulloch R, Hemsley J, Kelly P. Symptom management during chemotherapy. Paediatr. Child Heal. (United Kingdom) 2018; 28(4), 189-95. doi:10.1016/j.paed.2018.02.003

[6] Alcoser PW, Rodgers C. Treatment strategies in childhood cancer. J. Pediatr. Nurs. 2003; 18(2), 103-12. doi:10.1053/jpdn.2003.10

[7] Hedén L, Pöder U, Von Essen L, Ljungman G. Parents' perceptions of their child's symptom burden during and after cancer treatment. J. Pain Symptom Manage. 2013; 46(3), 366-75. doi:10.1016/j.jpainsymman.2012.09.012

[8] Selwood K, Ward E, Gibson F. Assessment and management of nutritional challenges in children's cancer care: A survey of current practice in the United Kingdom. Eur. J. Oncol. Nurs. 2010; 14(5), 439-46. doi:10.1016/j.ejon.2010.04.004

[9] Totadri S, Radhakrishnan V, Atreya H, Shenoy PK, Ganesan P, Ganesan TS, et al. Dietary perceptions and beliefs among families with children undergoing therapy for cancer. Pediatr. Hematol. Oncol. J. 2017; 2(2), 25-8. doi:10.1016/j.phoj.2017.06.004

[10] Sala A, Pencharz P, Barr RD. Children, Cancer, and Nutrition - A Dynamic Triangle in Review. Cancer 2004; 100(4), 677-87. doi:10.1002/cncr.11833 
[11] Sala A, Rossi E, Antillon F, Molina AL, De Maselli $T$, Bonilla $M$, et al. Nutritional status at diagnosis is related to clinical outcomes in children and adolescents with cancer: A perspective from Central America. Eur. J. Cancer 2012; 48(2), 243-52. doi:10.1016/j.ejca.2011.06.006

[12] Wilkes PA, Allen DH. Nutrition Care: Managing Symptoms From Cancer. J. Nurse Pract. 2018; 14(4), 267-275.e3.

doi:10.1016/j.nurpra.2018.01.011

[13] Virizuela JA, Camblor-Álvarez M, LuengoPérez LM, Grande E, Álvarez-Hernández J, Sendrós-Madroño MJ, et al. Nutritional support and parenteral nutrition in cancer patients: an expert consensus report. Clin. Transl. Oncol. 2018; 20(5), 619-29. doi:10.1007/s12094-017-1757-4

[14] American Cancer Society. Preventing Infections in People With Cancer 2015; https://www.cancer.org/treatment/treatment s-and-side-effects/physical-sideeffects/infections/preventing-infections-inpeople-with-cancer.html.

[15] Walter LM, Nixon GM, Davey MJ, Downie PA, Horne RSC. Sleep and fatigue in pediatric oncology: A review of the literature. Sleep Med. Rev. 2015; 24, 71-82. doi:10.1016/j.smrv.2015.01.001

[16] Phillips CR, Davis LL. Psychosocial Interventions for Adolescents and Young Adults with Cancer. Semin. Oncol. Nurs. 2015; 31(3), 242-50. doi:10.1016/j.soncn.2015.05.004

[17] Nance J, Santacroce SJ. Hematopoietic stem cell transplantation: Stress, psychoneurologic symptoms, and coping strategies in adolescents and young adults. Clin. J. Oncol. Nurs. 2017; 21(5), 531-3. doi:10.1188/17.CJON.531-533

[18] Gariépy N, Howe N. The therapeutic power of play: Examining the play of young children with leukaemia. Child. Care. Health Dev. 2003; 29(6), 523-37. doi:10.1046/j.13652214.2003.00372.x

[19] Nijhof SL, Vinkers CH, van Geelen SM, Duijff SN, Achterberg EJM, van der Net J, et al. Healthy play, better coping: The importance of play for the development of children in health and disease. Neurosci. Biobehav. Rev. 2018; 95(July), 421-9. doi:10.1016/j.neubiorev.2018.09.024

[20] Ghazisaeidi M, Safdari R, Goodini A, Mirzaiee $M$, Farzi J. Digital games as an effective approach for cancer management: Opportunities and challenges. J. Educ. Health Promot. 2017; 6(1), 30. doi:10.4103/jehp.jehp_146_14

[21] Suhonen K, Väätäjä H, Virtanen T, Raisamo R. Seriously Fun: Exploring How to Combine Promoting Health Awareness and Engaging Gameplay. MindTrek '08 Proc. 12th Int. Conf. Entertain. media ubiquitous era, Association for Computing Machinery (ACM); 2008, p. 18. doi:10.1145/1457199.1457204

[22] Charlier N, Zupancic N, Fieuws S, Denhaerynck K, Zaman B, Moons P. Serious games for improving knowledge and self-management in young people with chronic conditions: A systematic review and meta-analysis. J. Am. Med. Informatics Assoc. 2016; 23(1), 230-9. doi:10.1093/jamia/ocv100

[23] The University of Utah. Video Games Help Patients and Health Care Providers 2012; https://archive.unews.utah.edu/news_release s/video-games-help-patients-and-healthcare-providers/.

[24] Make-A-Wish Foundation of America. Ben's Video Game Fights Cancer 2012; http://wish.org/wishes/wish-stories/i-wishto-be/ben-video-game-creator.

[25] Voortman AJ. Serious Games: Learning skills by means of computer games. Vrije Universiteit Amsterdam, 2011.

[26] Gerling K, Fuchslocher A, Schmidt R, Krämer N, Masuch $M$. Designing and evaluating casual health games for children and teenagers with cancer. Lect. Notes Comput. Sci. (Including Subser. Lect. Notes Artif. Intell. Lect. Notes Bioinformatics) 2011; 6972 LNCS, 198-209. doi:10.1007/978-3-642-24500-8_21

[27] Bruggers CS, Baranowski S, Beseris M, Leonard R, Long D, Schulte $E$, et al. A Prototype Exercise-Empowerment Mobile Video Game for Children With Cancer, and Its Usability Assessment: Developing Digital 
Empowerment Interventions for Pediatric Diseases. Front. Pediatr. 2018; 6. 2018;6. doi:10.3389/fped.2018.00069

[28] Dictionary.com. Exergaming 2020; https://www.dictionary.com/browse/exerga ming.

[29] Hoffmann S, Wilson S. The role of serious games in the iManageCancer project. Ecancermedicalscience 2018; 12. doi:10.3332/ecancer.2018.850

[30] Kim HJ, Kim SM, Shin H, Jang JS, Kim YI, Han $\mathrm{DH}$. A mobile game for patients with breast cancer for chemotherapy self-management and quality-of-life improvement: Randomized controlled trial. J. Med. Internet Res. 2018; 20(10), e273. doi:10.2196/jmir.9559

[31] HopeLab. Re-Mission 2018; http://www.remission.net.

[32] Cole SW, Yoo DJ, Knutson B. Interactivity and reward-related neural activation during a serious videogame. PLoS One 2012; 7(3). doi:10.1371/journal.pone.0033909

[33] Kato PM, Cole SW, Bradlyn AS, Pollock BH. A Video Game Improves Behavioral Outcomes in Adolescents and Young Adults With Cancer: A Randomized Trial. Pediatrics 2008; 122(2), e305-17. doi:10.1542/peds.2007-3134

[34] Kayali F, Silbernagl M, Peters K, Mateus-Berr R, Reithofer A, Martinek D, et al. Design considerations for a serious game for children after hematopoietic stem cell transplantation. Entertain. Comput. 2016; 15, 57-73. doi:10.1016/j.entcom.2016.04.002

[35] Oxford University Press. Definition of cyber pet 2018; https://en.oxforddictionaries.com/definition/ us/cyberpet.

[36] Laskowski A. New Apps Teach Kids about Their Health. Bost. Univ. 2016; http://www.bu.edu/today/2016/wizdy-petseducates-kids-how-to-manage-asthmasymptoms/.

[37] Ahn SJG, Johnsen K, Robertson T, Moore J, Brown S, Marable A, et al. Using Virtual Pets to Promote Physical Activity in Children: An Application of the Youth Physical Activity Promotion Model. J. Health Commun. 2015;
20(7), 807-15. doi:10.1080/10810730.2015.1018597

[38] Ahn SJG, Johnsen K, Moore J, Brown S, Biersmith $M$, Ball C. Using Virtual Pets to Increase Fruit and Vegetable Consumption in Children: A Technology-Assisted Social Cognitive Theory Approach. Cyberpsychology, Behav. Soc. Netw. 2015; 19(2), 86-92. doi:10.1089/cyber.2015.0224

[39] Brown E, Cairns P. A grounded investigation of game immersion. Ext. Abstr. 2004 Conf. Hum. Factors Comput. Syst. - CHI '04, 2004, p. 1297300. doi:10.1145/985921.986048

[40] Wang H, Sun CT. Game reward systems: Gaming experiences and social meanings. Proc. DiGRA 2011 Conf. Think Des. Play 2011; (March).

[41] Richter G, Raban D, Rafaeli S. Studying Gamification: The Effect of Rewards and Incentives on Motivation. Gamification Educ. Bus. 2014; 21-46. doi:10.1007/978-3-31910208-5_2.

[42] Soutter ARB, Hitchens $M$. The relationship between character identification and flow state within video games. Comput. Human Behav. 2016; 55, 1030-8. doi:10.1016/j.chb.2015.11.012

[43] Heikkinen K. How to Keep Your Players in Game with Appointment Mechanics. GameRefinery 2019; https://www.gamerefinery.com/keep-yourplayers-in-game-with-appointmentmechanics/.

[44] Maddux JE, Rogers RW. Protection motivation and self-efficacy: A revised theory of fear appeals and attitude change. J. Exp. Soc. Psychol. 1983; 19(5), 469-79. doi:10.1016/0022-1031(83)90023-9

[45] Chittaro L, Sioni R. Serious games for emergency preparedness: Evaluation of an interactive vs. a non-interactive simulation of a terror attack. Comput. Human Behav. 2015; 50, 508-19. doi:10.1016/j.chb.2015.03.074

[46] Bui L, Mullan B, Mccaffery K. Protection motivation theory and physical activity in the general Population: A systematic literature review. Psychol. Heal. Med. 2013; 18(5), 52242. doi:10.1080/13548506.2012.749354 
[47] Baghianimoghadam $\mathrm{MH}$, Mohammadi S, Noorbala MT, Mazloomy SS. An intervention based on protection motivation theory in reducing skin cancer risk. J. Pakistan Assoc. Dermatologists 2011; 21(3), 141-8.

[48] Wu YP, Nagelhout E, Aspinwall LG, Boucher K, Parsons BG, Kohlmann W, et al. A novel educational intervention targeting melanoma risk and prevention knowledge among children with a familial risk for melanoma. Patient Educ. Couns. 2018; 101(3), 452-9. doi:http://dx.doi.org/10.1016/j.pec.2017.10.0 08

[49] Bandura A, Walters RH. Social learning theory. Englewood Cliffs, NJ: Prentice-hall; 1977. doi:10.1111/j.1460-2466.1978.tb01621.x

[50] Mayes JT. Still to learn from vicarious learning. E-Learning Digit. Media 2015; 12(3-4), 361-71. doi:10.1177/2042753015571839

[51] Cherry K. How Social Learning Theory Works. Dotdash 2019; https://www.verywellmind.com/sociallearning-theory-2795074.

[52] Farrow C, Belcher E, Coulthard H, Thomas JM, Lumsden J, Hakobyan $L$, et al. Using repeated visual exposure, rewards and modelling in a mobile application to increase vegetable acceptance in children. Appetite 2019; 141(March), 104327.

[53] Barbosa DNF, Bassani PBS, Mossmann JB, Schneider GT, Reategui E, Branco M, et al. Mobile learning and games: Experiences with mobile games development for children and teenagers undergoing oncological treatment. Lect. Notes Comput. Sci. (including Subser. Lect. Notes Artif. Intell. Lect. Notes Bioinformatics), vol. 8395 LNCS, Springer Verlag; 2014, p. 153-64. doi:10.1007/978-3319-05972-3_16

[54] Baggott C, Baird J, Hinds P, Ruland CM, Miaskowski C. Evaluation of Sisom: A computer-based animated tool to elicit symptoms and psychosocial concerns from children with cancer. Eur. J. Oncol. Nurs. 2015; 19(4), 359-69. doi:10.1016/j.ejon.2015.01.006

[55] Oliemat E, Ihmeideh F, Alkhawaldeh M. The use of touch-screen tablets in early childhood: Children's knowledge, skills, and attitudes towards tablet technology. Child. Youth Serv. Rev. 2018; 88, 591-7. doi:10.1016/j.childyouth.2018.03.028 